\title{
Effects of Temperature Gradients and Heat Fluxes on High Temperature Oxidation
}

\section{Gordon R. Holcomb ${ }^{1}$}

\begin{abstract}
(1) Materials Performance Division, National Energy Technology Laboratory, Albany, OR, USA,
\end{abstract} Gordon.Holcomb@netl.doe.gov

\begin{abstract}
The effects of a temperature gradient and heat flux on point defect diffusion in protective oxide scales were examined. Irreversible thermodynamics were used to expand Fick's first law of diffusion to include a heat flux term - a Soret effect. Oxidation kinetics were developed for the oxidation of cobalt and of nickel doped with chromium. Research is described to verify the effects of a heat flux by oxidizing pure cobalt in a temperature gradient at $900^{\circ} \mathrm{C}$, and comparing the kinetics to isothermal oxidation. No evidence of a heat flux effect was found.
\end{abstract}

Key Words: Heat of Transport, Temperature Gradient, Soret, Cobalt, Oxidation

\section{Introduction}

In fossil energy power plants there are many components that undergo oxidation under large temperature gradients and high heat fluxes. Examples include blades and vanes in turbines, and superheater and evaporator tubes in boilers. Cutler and Raask ${ }^{1}$ report heat fluxes on the order of 200 $\mathrm{kW} / \mathrm{m}^{2}$ in superheaters and $400 \mathrm{~kW} / \mathrm{m}^{2}$ in evaporator tubes.

Early efforts that examined the role of heat flux upon oxidation concerned superheated steam pipes. When compared with isothermal exposures, both the water-side oxidation rate and the degree of scale exfoliation increased for pipes made of $2 \frac{1}{4} \mathrm{Cr}-1 \mathrm{Mo}$ steel (metal surface temperatures of $496-541{ }^{\circ} \mathrm{C}$, heat flux of $\left.126 \mathrm{~kW} / \mathrm{m}^{2}\right),{ }^{2}$ Inconel $625\left(565-621^{\circ} \mathrm{C}\right),{ }^{3}$ and Incoloy $800\left(565-621^{\circ} \mathrm{C}\right){ }^{4}$ In contrast, no difference in oxidation rates was observed between isothermal and heat flux exposures for either $12 \mathrm{Cr} 1 \mathrm{MoV}$ pearlitic steel or $\mathrm{Cr} 18 \mathrm{Ni10Ti}$ austenitic steel $\left(405-550^{\circ} \mathrm{C}\right) .^{5}$

Oxidation and corrosion behavior in the presence of a temperature gradient can be different with respect to isothermal conditions. For example: 1) thermal gradients can modify the thermal stress distribution within the scale and thus change scale adhesion and scale cracking behavior; 2) deposition of corrosive species in fireside corrosion can change as a function of heat flux due to changes in surface temperatures; ${ }^{6} 3$ ) fireside temperatures can increase when maintaining target steam temperatures due to insulating oxides growing within boiler tubes; and 4) point defect diffusion within oxide scales can change- either from a straightforward temperature effect (diffusion being faster with increasing temperature) or from heat of transport effects (how the heat carried with each atomic jump can effect diffusion - the Soret effect). It is this last pair of items, the diffusion aspects during oxidation in temperature gradients, which are addressed here.

The goal of this research is to understand the effects of temperature gradients and heat fluxes on the oxidation of pure and singly-doped metals. It is hoped that this could lead to an improved understanding of the oxidation of alloys and alloy-coating systems, and to allow for better use of isothermal laboratory data as a predictor of actual service life.

The theoretical background for oxidation rate changes in high heat flux conditions are presented for the oxidation of pure cobalt and of nickel doped with chromium. Experimental verification using the oxidation of pure cobalt in a temperature gradient is described. 


\section{Theory}

Temperature gradients in a solid oxide result in two changes that modify diffusion. The first is because equilibrium concentrations of point defects are a function of temperature. The gradient in point defect concentration that normally exists during oxidation can be modified within the oxide. An example would be when more vacancies are expected at higher temperatures. The second change is associated with the heat carried with each diffusion jump of an atom - the Soret effect. Since each jump results in a transport of heat, the presence of a temperature gradient biases the jumps. This transport of heat is described by the heat of transport, $Q^{*}$, which is the heat carried from the initial site to the final site. ${ }^{[1]}$

Both Glover $^{7}$ and Malik ${ }^{8-9}$ have used non-equilibrium thermodynamics ${ }^{10}$ to develop general flux equations that can be combined with point defect information of specific oxides to predict oxidation rates. The general flux equation, from Malik ${ }^{8-9}$ is:

$$
J_{i}=-\frac{N c_{i} D_{i}}{k_{B} T}\left\{\left(1-t_{i}\right)\left[\frac{d \mu_{i}}{d x}+\frac{Q_{i}^{*} d T}{T d x}\right]-q_{i} \sum_{k \neq i} \frac{t_{k}}{q_{k}}\left(\frac{d \mu_{k}}{d x}+\frac{Q_{k}^{*} d T}{T d x}\right)\right\}
$$

where $\mathrm{J}_{\mathrm{i}}$ is the flux of species $\mathrm{i}$ in the oxide, $\mathrm{N}$ is the number of lattice sites available to species i per unit volume, $c_{i}$ is the concentration of species $i, D_{i}$ is the diffusion coefficient of species $i, k_{B}$ is Boltzmann's constant, $T$ is absolute temperature, $t_{i}$ is the transport number of species $i, \mu_{i}$ is the chemical potential of species $\mathrm{i}, \mathrm{x}$ is the distance into the oxide from the metal, and $\mathrm{q}_{\mathrm{i}}$ is the effective charge of species $\mathrm{i}$. Equation 1 differs from that given by Glover ${ }^{7}$ by including the consequences of effective charge on the diffusion process $\left(t_{i}\right.$ and the $\mathrm{q}_{\mathrm{i}} \Sigma()$ term). When the temperature gradient is zero and neglecting any effects of effective charge, then Eq. 1 simplifies to Fick's first law of diffusion. Some of these terms are further defined as:

$$
\begin{aligned}
& \mu_{i}=\mu_{i}^{\circ}+k_{B} T \ln c_{i} \\
& t_{i}=\frac{D_{i} N e_{i}^{2} c_{i}}{k_{B} T \sigma} \\
& \sigma=\sum \frac{D_{i} N e_{i}^{2} c_{i}}{k_{B} T}
\end{aligned}
$$

where $\mu_{\mathrm{i}}{ }^{\circ}$ is the chemical potential of $i$ at standard state, $e_{i}$ is the charge of $i$, and $\sigma$ is the conductivity.

\section{Oxidation of Pure Cobalt to $\mathrm{CoO}$}

To apply Eq. 1 to a particular system, details of the defect structure and transport properties must be available or assumed. For cobalt, $\mathrm{CoO}$ is a metal deficient $\left(\mathrm{Co}_{1-\mathrm{y}} \mathrm{O}\right)$, p-type semiconductor that is approximately stoichiometric when in equilibrium with cobalt metal. ${ }^{11}$ The predominant point defects are cation vacancies, singly-charged (relative to the cobalt matrix) at moderate to high oxygen partial pressures $\left(\mathrm{P}_{\mathrm{O} 2}\right)$ and doubly-charged at low $\mathrm{P}_{\mathrm{O} 2}$. Assuming that the predominant point defects are singlycharged vacancies, their formation can be described with Kröger-Vink notation by

$$
\frac{1}{2} \mathrm{O}_{2}=V_{C o}^{\prime}+h^{\bullet}+O_{O}^{X}
$$

where $\mathrm{V}^{\prime}{ }_{\mathrm{Co}}$ is a singly-charged cobalt vacancy, $\mathrm{h}$ is an electron hole and $\mathrm{O}^{\mathrm{x}}{ }_{\mathrm{O}}$ is an oxygen ion an oxygen site. Using the law of mass action, the corresponding defect equilibrium is

\footnotetext{
${ }^{[1]} \mathrm{A}$ similar term found in the literature is the reduced heat of transport, $\mathrm{Q}^{*}$, which is the portion of $\mathrm{Q}^{*}$ in excess of the partial molar enthalpy, h. Thus $\mathrm{Q}^{* \prime}=\mathrm{Q}^{*}-\mathrm{h}$.
} 


$$
\left[V_{C o}^{\prime}\right] p=K_{V_{C o}^{\prime}} P_{O_{2}}^{\frac{1}{2}}
$$

where $\mathrm{p}$ is the concentration of electron holes and $\mathrm{K}_{\mathrm{V}^{\prime} \mathrm{co}}$ is the equilibrium constant of Eq. 5 . When impurities, intrinsic ionization, and minority defects are neglected, the simplified electrical neutrality condition becomes

$$
\left[V_{C o}^{\prime}\right]=p=K_{V_{C o}^{\prime}}^{\frac{1}{2}} P_{O_{2}}^{\frac{1}{4}}
$$

The mobility of electron holes is much larger than that of cobalt vacancies, so the approximation was made that $\mathrm{t}_{\mathrm{h}} \approx 1$ and $\mathrm{t}_{\mathrm{V}^{\prime} \text { co }} \approx 0$. Other assumptions are that $\mathrm{J}_{\mathrm{Co}}$ is, at any given time, the same at all points within the oxide scale, the temperature profile is linear across the oxide scale, $\mathrm{Q}_{\mathrm{i}}{ }^{*}$ values are independent of temperature, $\mathrm{Q}_{\mathrm{h}}{ }^{*}<<\mathrm{Q}_{\mathrm{V}^{\prime}{ }^{\prime} o}{ }^{*}$, and $\mathrm{Q}_{\mathrm{V}^{\prime} \mathrm{co}}{ }^{*}=-\mathrm{Q}_{\mathrm{Co}}{ }^{*}$. After these assumptions are made, the resulting expression from the integration ${ }^{[1]}$ of Eq. 1 is $^{8-9}$

$$
J_{C o}=\left(\frac{4 k_{B} N D_{o}}{Q_{C o}^{*}+2 h_{v}}\right)\left(\frac{T_{L}-T_{0}}{L}\right)\left[\frac{\left[V_{C o}^{\prime}(L)\right] \exp \left(\frac{Q_{C o}^{*}}{2 k_{B} T_{L}}\right)-\left[V_{C o}^{\prime}(0)\right] \exp \left(\frac{Q_{C o}^{*}}{2 k_{B} T_{0}}\right)}{f\left(g_{0}\right)-f\left(g_{L}\right)}\right]
$$

where $D_{0}$ is the frequency factor in the Arrhenius expression for vacancy diffusion $\left(D_{V^{\prime} c o}=D_{0} \exp (-\right.$ $\left.\mathrm{h}_{\mathrm{v}} / \mathrm{RT}\right)$ ), $\mathrm{h}_{\mathrm{v}}$ is the activation energy for vacancy diffusion, and $\mathrm{L}$ and 0 refer to the oxide-gas and metaloxide interfaces ( $\mathrm{L}$ is the scale thickness). The $\mathrm{f}\left(\mathrm{g}_{\mathrm{i}}\right)$ terms are evaluated using

$$
\begin{aligned}
& g_{i}=\frac{Q_{C o}^{*}+2 h_{v}}{2 k_{B} T_{i}} \\
& f(g)=-\frac{e^{g}}{g}+\ln |g|+g+\frac{g^{2}}{2 \times 2 !}+\frac{g^{3}}{3 \times 3 !}+\ldots+\text { many terms for convergence }
\end{aligned}
$$

Note in Eq. 8 that $\mathrm{J}_{\mathrm{Co}}$ is inversely proportional to the scale thickness $\mathrm{L}$, which is consistent with parabolic oxidation kinetics. Also note that as $\mathrm{T}_{\mathrm{L}}-\mathrm{T}_{0}$ approaches zero, the numerator of the second term and the denominator of the third term both approach zero. While the many terms needed for convergence in Eq. 10 prevent a tractable algebraic proof, numerically it can be shown that the flux converges with isothermal behavior as $\mathrm{T}_{\mathrm{L}}-\mathrm{T}_{0}$ approaches zero.

After $\mathrm{J}_{\mathrm{Co}}$ is known as a function of scale thickness, Eq. 8 can be integrated to obtain scale thickness as a function of time. The parameters used to find $\mathrm{J}_{\mathrm{Co}}$ as a function of scale thickness are given in Table 1. $\left[\mathrm{V}^{\prime}{ }_{\mathrm{Co}}\right]$ is a function of position, where 0 is at the metal/scale interface and $\mathrm{x}$ is at the scale/gas interface. The value of $\mathrm{Q}_{\mathrm{Co}}{ }^{*}$ is not known. Glover ${ }^{7}$ approximated it with the activation energy for vacancy diffusion, $h_{v}$, and Malik ${ }^{8-9}$ equated it with various multiples of $h_{v}$ (e.g. $-1,0,1$, and 2 ). In Table 1 , a representative value of $100 \mathrm{~kJ} / \mathrm{mol}$ was used.

For illustration purposes, Eq. 8 was integrated with boundary conditions were chosen such that $\mathrm{T}_{0}$ and $\mathrm{T}_{\mathrm{L}}$ maintained constant values of $1000^{\circ} \mathrm{C}$ and $1050^{\circ} \mathrm{C}$. The partial pressure of oxygen in the gas was 0.21 (air). Figure 1 shows the results of this integration - the " $\mathrm{dT} / \mathrm{dx}, \mathrm{Q}=100 \mathrm{~kJ} / \mathrm{mol}$ " curve. To separate the effects of heat of transport effects from the effects of a temperature gradient on point defect concentration, the same calculations were made except with $\mathrm{Q}_{\mathrm{Co}_{\mathrm{o}}}{ }^{*}=0$ - the " $\mathrm{dT} / \mathrm{dx}, \mathrm{Q}=0$ " curve. These

${ }^{[1]}$ The integration is of the form $\int \frac{e^{g}}{g^{2}} d x$, where g is defined in Eq. 9 and then solved. ${ }^{12}$ 
both lie between the isothermal curves at $1050^{\circ} \mathrm{C}$ and $1000^{\circ} \mathrm{C}$. The " $\mathrm{dT} / \mathrm{dx}, \mathrm{Q}=100 \mathrm{~kJ} / \mathrm{mol}$ " shows how the heat of transport can decrease the oxidation rate. A negative heat of transport, as typical with interstitials, would increase the corrosion rate. Figure 1 shows that the effects of a temperature gradient on the oxidation kinetics are quite modest. However, the selection of boundary conditions makes a large difference in the effect. In Fig. 1, the heat flux and temperature gradient decrease with increasing scale thickness and time. When the temperature gradient and metal temperature are fixed, then a much larger effect is observed. Also shown in Fig 1 as dashed lines are the isothermal scale thicknesses derived from Mrowec and Prybyski, ${ }^{15}$ where the oxidation of Cobalt was examined over a wide range of temperatures $\left(950-1300^{\circ} \mathrm{C}\right)$ and oxygen partial pressures. The Mrowec and Prybyski ${ }^{15}$ results are much lower than the isothermal predictions of the model, but have much the same temperature dependence. The values from Table 1 for $\mathrm{D}_{\mathrm{o}},\left[\mathrm{V}^{\prime}{ }_{\mathrm{Co}}(\mathrm{L})\right]$, and $\left[\mathrm{V}^{\prime}{ }_{\mathrm{Co}}(0)\right]$ are the most likely sources of disagreement.

\section{Oxidation of Cr Doped Nickel to NiO}

A similar treatment, based on Eq. 1, can be made for more complex systems. One example is nickel doped with chromium. Up to the solubility limit, where $\mathrm{NiCr}_{2} \mathrm{O}_{4}$ forms, trivalent chromium occupies divalent nickel sites, $\mathrm{Cr}_{\mathrm{Ni}}$. Above $850^{\circ} \mathrm{C}$, electrical neutrality is maintained with doubly charged nickel vacancies, $\mathrm{V}^{\prime \prime}{ }_{\mathrm{Ni}}{ }^{16}$ The formation of these defects is described by

$$
\mathrm{Cr}_{2} \mathrm{O}_{3}=2 \mathrm{Cr}_{\mathrm{Ni}}^{\bullet}+3 \mathrm{O}_{\mathrm{O}}^{x}+\mathrm{V}_{\mathrm{Ni}}^{\prime \prime}
$$

The simplified electrical neutrality condition is

$$
\left[C r_{\text {total }}\right]=\left[C r_{N i}^{\bullet}\right]=2\left[V_{N i}^{\prime \prime}\right]
$$

Since the jump frequency of chromium ion-vacancy exchange is approximately one tenth of the jump frequency for nickel ion-vacancy exchange, ${ }^{17}$ the transport number of $\mathrm{V}^{\prime \prime}{ }_{\mathrm{Ni}}$ can be approximated ${ }^{[1]}$ by $20 / 21$ and of $\mathrm{Cr}_{\mathrm{Ni}}$ by $1 / 21$. The chromium solubility is low, so $\mathrm{J}_{\mathrm{Ni}}$ is approximately equal to $-\mathrm{J}_{\mathrm{Vni}}$. In a similar fashion as was done for Eqs. 8-10, the resulting flux from Eq. 1 becomes

$$
\begin{aligned}
& J_{N i}=\left(\frac{9 k_{B} N D_{o}}{42\left(3 h_{v}-Q_{V}^{*}-2 Q_{C r}^{*}\right)}\right)\left(\frac{T_{L}-T_{0}}{L}\right)\left[\frac{\left[C_{N i}(L)\right] \exp \left(-\frac{Q_{V}^{*}+2 Q_{C r}^{*}}{3 k_{B} T_{L}}\right)-\left[C_{N i}(0)\right] \exp \left(-\frac{Q_{V}^{*}+2 Q_{C r}^{*}}{3 k_{B} T_{0}}\right)}{f\left(g_{0}\right)-f\left(g_{L}\right)}\right] \\
& g_{i}=\frac{3 h_{v}-Q_{V}^{*}-2 Q_{C r}^{*}}{3 k_{B} T_{i}}
\end{aligned}
$$

\section{Experimental Procedures}

In an attempt to verify the theory of oxidation in a temperature gradient, Malik ${ }^{8-9}$ examined the oxidation of nickel at 600 to $900^{\circ} \mathrm{C}$. The results were inconclusive. Besides the inherent difficulty in measuring what may be a small effect (depending upon the value of $\mathrm{Q}_{\mathrm{Ni}}{ }^{*}$ ), there were other factors that could have masked the effect. One factor was that the defect structure of $\mathrm{NiO}$ is quite dependant upon impurity levels, which are very hard to control. A second factor is that much of the temperature range was below $800^{\circ} \mathrm{C}$, where grain boundary diffusion becomes more predominant than lattice diffusion. In the present investigation, cobalt oxidation above $800^{\circ} \mathrm{C}$ was selected because: 1) the defect structure of $\mathrm{CoO}$ is much less susceptible to impurity effects; 2) above $800^{\circ} \mathrm{C}$ lattice diffusion should predominate;

${ }^{[1]}$ The transport number is $\mathrm{D}_{\mathrm{i}} \mathrm{Nq}_{\mathrm{i}}{ }^{2} \mathrm{C}_{\mathrm{i}} / \Sigma\left(\mathrm{D}_{\mathrm{i}} \mathrm{Nq}_{\mathrm{i}}{ }^{2} \mathrm{C}_{\mathrm{i}}\right)$, so $\mathrm{t}_{\mathrm{v}} \approx 10 \cdot 2^{2} \cdot 1 /\left(10 \cdot 2^{2} \cdot 1+1 \cdot 1^{2} \cdot 2\right)=20 / 21$ and $\mathrm{t}_{\mathrm{Cr}} \approx 1 / 21$. 
and 3) cobalt oxidation has been the subject of much study, so many of the model parameters are known. Also, like $\mathrm{NiO}, \mathrm{CoO}$ forms a dense and adherent scale, which is needed for the temperature cycling inherent in the periodic measurements of scale thickness. Figure 2 shows the temperature and oxygen partial pressure limits for the experiments. The oxygen partial pressure $\left(\mathrm{N}_{2}-1 \% \mathrm{O}_{2}\right)$ is below the level where duplex $\mathrm{CoO}+\mathrm{Co}_{3} \mathrm{O}_{4}$ scales form, ${ }^{11}$ so only $\mathrm{CoO}$ forms, but above the level where doubly charged cobalt vacancies, $\mathrm{V}^{\prime \prime}{ }_{\mathrm{Co}}$, become an important point defect, ${ }^{11}$ so the approximation of Eq. 6 is suitable for the majority of the oxide scale. The temperature is above $800^{\circ} \mathrm{C}$, so lattice diffusion predominates.

The overall experimental procedure closely follows that used by Malik, ${ }^{8-9}$ which consisted of oxidizing one side of a piece of cobalt ( 0.9995 pure), while cooling the other side and measuring the temperature gradient across the sample. This established a known temperature gradient across the metal sample from which the heat flux was calculated using the thermal conductivity of cobalt. After exposure to oxygen at temperature, the sample was removed from the furnace, the oxide scale nicked with a drill bit at a $45^{\circ}$ angle, and the thickness of the scale measured with scanning electron microscopy (SEM) of the nick. The sample was then available for further oxidation.

A sample assembly is shown in Fig. 3. It consists of a 1 inch $(2.54 \mathrm{~cm})$ diameter cobalt disk machined so that two thermocouples can be inserted and six small bolts can attach it to a stainless steel air-cooled chamber. The two thermocouples were offset from each other and at depths of $2.3 \mathrm{~mm}$ and 4.6 $\mathrm{mm}$ from the disk surface. Different conductivity materials were placed in between the sample and the air-cooled chamber: a stainless steel mesh for heat flux experiments and an alumina disk for experiments that were closer to isothermal conditions. The heat flux experiments used a cooling air flow rate of 20 $\mathrm{L} / \mathrm{min}$. The closer-to-isothermal experiments used a cooling air flow rate of $2 \mathrm{~L} / \mathrm{min}$ so as to protect the cooling chamber from overheating. The rest of the sample assembly, shown in Fig. 4, is wrapped in insulation and inserted into a tube furnace, Fig. 5. The insulation wrap includes covering the outer circumference of the sample, to approximate one-dimensional heat flow within the sample.

The sample assembly was heated to temperature while exposed to $\mathrm{N}_{2}$. For the heat flux tests the furnace temperature was approximately $1150^{\circ} \mathrm{C}$. For the closer-to-isothermal tests the furnace temperature was approximately $920^{\circ} \mathrm{C}$. In both cases the furnace temperature was adjusted to obtain a metal surface temperature of $900^{\circ} \mathrm{C}$. Then $1 \% \mathrm{O}_{2}$ was added to the $\mathrm{N}_{2}$ to start the oxidation test.

\section{Results and Discussion}

An example of the temperatures measured within the cobalt disk during an experiment is shown in Fig. 6, where $T_{1}$ is the deepest thermocouple and $T_{2}$ is the shallowest thermocouple. The temperature of the metal surface was calculated assuming a linear temperature gradient. Throughout the experiment the furnace temperature was adjusted to maintain the metal surface temperature close to $900^{\circ} \mathrm{C}$.

The heat flux was calculated using:

Heat Flux $\left(\mathrm{kWm}^{-2}\right)=10 k_{\mathrm{Co}}\left(\mathrm{Wcm}^{-1} \mathrm{~K}^{-1}\right) \frac{T_{2}-T_{1}}{L(\mathrm{~cm})}$

where $\mathrm{k}_{\mathrm{Co}}$ is the thermal conductivity of cobalt and $\mathrm{L}$ is the depth difference between the two thermocouples $(0.23 \mathrm{~cm})$. The thermal conductivity of cobalt was derived from Ho et al. ${ }^{18}$ $k_{C o}\left(W_{c m}^{-1} K^{-1}\right)=-0.0001463 T\left({ }^{\circ} \mathrm{C}\right)+0.6274\left\{700^{\circ}-1000^{\circ} \mathrm{C}, \mathrm{R}^{2}=0.993\right\}$

The oxide scale thickness was measured by nicking the surface at a $45^{\circ}$ angle with a 0.040 inch (1 $\mathrm{mm}$ ) diameter drill bit and examining the nick with back-scattered electron (BSE) images. Figures 7-8 show BSE images of the nick for the longest duration close-to-isothermal test (Fig. 7) and the longest duration heat flux test (Fig. 8). Due to the $45^{\circ}$ angle of the nick, the scale thickness was the same as the widths found on Figs. 7-8 between the lighter shaded cobalt metal and the undisturbed oxide scale surface, measured on the side of the nick away from the base of the drilled hole. 
The results for all of the tests are shown in Table 2, with the heat flux tests on rows 1-5 and the closer-to-isothermal tests on rows 6-10. Measuring scale thickness with BSE of a nick allowed a sample to be reinserted into the apparatus for further exposure. The first four heat flux tests and the first four closer-to-isothermal tests shown in Table 2 used this procedure to obtain multiple oxide thickness measurements on the same sample as a function of exposure time. A longer duration test (500 and 476 hrs) of each type was also done without removal from the furnace.

The two sets of oxide thickness data nearly overlap each other, as shown as data points and dashed lines in Fig. 9. No effect is seen from the heat flux or temperature gradient.

As Fig. $9 \mathrm{~b}$ shows, the experimental data differ from parabolic kinetics, especially at short times. Yet the results of Mrowec and Prybylski ${ }^{15}$ clearly show parabolic behavior even at short durations. This non-parabolic behavior could be due to inaccuracies in the measurement of small scale thicknesses at short exposure times. The standard deviations of scale thickness values after short durations (Table 2) are a much larger fraction of the scale thickness than at longer durations. Inherent in measuring scale thickness is determining exactly where the top and bottom of the scale lie. It is possible that this caused a systematic under measurement error in scale thickness.

Also on Fig. 9 are illustrative calculations from Eq. 8. The isothermal line was calculated with $\mathrm{Q}_{\mathrm{Co}}{ }^{*}=0, \mathrm{~T}_{0}=900^{\circ} \mathrm{C}$, and $\mathrm{T}_{\mathrm{x}}=\mathrm{T}_{0}+10^{-6}{ }^{\circ} \mathrm{C}$. The other three lines were calculated with $\mathrm{T}_{0}=900^{\circ} \mathrm{C}, \mathrm{T}_{\mathrm{x}}=$ $1080^{\circ} \mathrm{C}$ and three values of $\mathrm{Q}_{\mathrm{Co}}{ }^{*}$. The results of Mrowec and Prybylski ${ }^{15}$ were extrapolated down to $900^{\circ} \mathrm{C}$ (from $950^{\circ} \mathrm{C}-1300^{\circ} \mathrm{C}$ ) and shown in Fig. 9. As in Fig 1, the calculated oxidation curves from Eq. 8 are higher than the extrapolation from Mrowec and Prybylski. ${ }^{15}$ The curves extrapolated from Mrowec and Prybylski ${ }^{15}$ somewhat agree with the experimental data, with the main difference being slower initial oxidation for the experimental data.

\section{Conclusions}

The presence of high heat fluxes and temperature gradients in many fossil energy systems creates the need for an understanding of their effects on corrosion and oxidation. The combined effects of temperature gradients on point defect concentration and mobility (heat of transport effects) are described with a theory of oxidation kinetics in a temperature gradient. Kinetic equations were developed for the oxidation of pure cobalt and of nickel doped with chromium.

An attempt to verify the theory was made by oxidizing pure cobalt at $900^{\circ} \mathrm{C}$ with $\mathrm{N}_{2}-1 \% \mathrm{O}_{2}$. Scale thicknesses were the same either with a heat flux or at near isothermal conditions. No heat flux effect was observed.

\section{References}

1. A. J. B. Cutler, E. Raask, Corrosion Science, Vol. 21, 1981, pp. 789-800.

2. J. C. Griess, J. H. DeVan, W. A. Maxwell, Materials Performance, Vol. 36, June 1980, pp. 46-52.

3. W. L. Pearl, E. G. Brush, G. G. Gaul, S. Leistikow, Nuclear Applications, Vol. 3, 1967, pp. 418-432.

4. W. L. Pearl, E. G. Brush, G. G. Gaul, G. P. Wozadlo, Nuclear Applications, Vol. 1, 1965, pp. 235245.

5. V. P. Glebov, V. M. Zusman, V. A. Taratuta, Thermal Engineering, Vol. 24, October 1977, pp. 4548.

6. F. Uberti, A Colombo, G. P. De Gaudenzi, G. Rocchini, Materials Science Forum, Vols. 251-254, 1997, pp. 657-664. 
7. D. M. Glover, Corrosion Science, Vol. 20, 1980, pp. 1185-1193.

8. S. Malik, "Oxidation of Metals in a Temperature Gradient," Ph.D. Thesis, University of Kent at Canterbury (1990).

9. S. Malik, A. V. Chadwick, "Oxidation in a Temperature Gradient," Microscopy of Oxidation, Eds. M. J. Bennet, G. W. Lorimer (Institute of Metals, London, 1991), pp. 336-341.

10. R. E. Howard, A. B. Lidiard, Reports on Progress in Physics, Vol. 27, 1964, pp. 161-240.

11. P. Kofstad, High Temperature Corrosion, (Elsevier Applied Science, New York, 1988) pp. 93-100 (Ch 4), 183-186 (Ch 6).

12. Handbook of Chemistry and Physics, editors R. C. Weast and M. J. Astle, 59th Ed, (CRC Press, Boca Raton, Florida, 1978-1979) p. A-82.

13. G. J. Koel, P. J. Gellings, Oxidation of Metals, Vol. 5, 1972, pp. 185-203.

14. O. Kubaschewski, C. B. Alcock, Metallurgical Thermochemistry, 5th Ed, (Pergamon Press, New York, 1979) p. 379 (Table E).

15. S. Mrowec, K. Przybylski, Oxidation of Metals, Vol. 11, 1977, pp. 365-381.

16. G. H. Meier, R. A. Rapp, Zeitschrift für Physikalische Chemie, Vol. 54, 1971, pp. 168-189.

17. R. A. Perkins, R. A. Rapp, Metallurgical Transactions, Vol. 4, 1973, pp. 193-205.

18. C. Y. Ho, R. W. Powell, P. E. Liley, Journal of Physical and Chemical Reference Data, Vol. 1, 1972, pp. 279-427. 
Table 1. Parameters used for oxidation of cobalt in a temperature gradient.

\begin{tabular}{lll}
\hline Parameter & Value & Reference \\
\hline $\mathrm{D}_{\mathrm{o}}$ & $0.02 \mathrm{~cm}^{2} / \mathrm{s}$ & Koel and Gellings \\
$\mathrm{N}$ & $5.18 \cdot 10^{22}$ sites $/ \mathrm{cm}^{3}$ & Malik $^{8}$ \\
$\mathrm{~h}_{\mathrm{v}}$ & $109 \mathrm{~kJ} / \mathrm{mol}$ & Koel and Gellings \\
{$\left[\mathrm{V}^{\prime}{ }_{\mathrm{Co}}(\mathrm{L})\right]$} & $0.147 \exp (-3925 / \mathrm{T}) \mathrm{P}_{\mathrm{O} 2}{ }^{1 / 4}$ vacancies $/$ site & Koel and Gellings \\
{$\left[\mathrm{V}^{\prime}{ }_{\mathrm{Co}}(0)\right]$} & $0.147 \exp (-4.252-17990 / \mathrm{T})$ vacancies $/ \mathrm{site}$ & Koel and Gellings ${ }^{13}$ with Kubaschewski and \\
& & $\begin{array}{l}\text { Alcock }{ }^{14} \text { for } 2 \mathrm{CoO}=2 \mathrm{Co}+\mathrm{O}_{2} \text { equilibrium at } \\
\text { the metal-oxide interface }\end{array}$ \\
$\mathrm{Q}_{\mathrm{Co}}{ }^{*}$ & $100 \mathrm{~kJ} / \mathrm{mol}$ & Representative value (see text) \\
\hline
\end{tabular}

Table 2. Experimental results for exposures of cobalt in a $\mathrm{N}_{2}-1 \% \mathrm{O}_{2}$ atmosphere with an approximate metal surface temperature of $900^{\circ} \mathrm{C}$.

\begin{tabular}{|c|c|c|c|c|c|c|c|c|c|}
\hline $\begin{array}{r}\text { Cooling } \\
\text { Air, } \\
\text { L/min }\end{array}$ & Insert & $\begin{array}{r}\text { Start } \\
\text { Time, } \\
\text { hr }\end{array}$ & $\begin{array}{r}\text { End } \\
\text { Time, } \\
\text { hr }\end{array}$ & $\begin{array}{r}\text { Max } \\
\text { Surface } \\
\text { Temp, } \\
{ }^{\circ} \mathrm{C}\end{array}$ & $\begin{array}{r}\text { Mean } \\
\text { Surface } \\
\text { Temp, } \\
{ }^{\circ} \mathrm{C}\end{array}$ & $\begin{array}{r}\text { Max } \\
\text { Heat } \\
\text { Flux, } \\
\mathrm{kW} / \mathrm{m}^{2}\end{array}$ & $\begin{array}{r}\text { Mean } \\
\text { Heat } \\
\text { Flux, } \\
\mathrm{kW} / \mathrm{m}^{2}\end{array}$ & \multicolumn{2}{|c|}{$\begin{array}{c}\text { Oxide } \\
\text { Thickness, } \\
\mu \mathrm{m}\end{array}$} \\
\hline 20 & SS Mesh & 0.0 & 9.2 & 925 & 919 & 237 & 227 & & \\
\hline 20 & SS Mesh & 9.2 & 33.2 & 903 & 893 & 275 & 273 & 21.0 & \pm 6.4 \\
\hline 20 & SS Mesh & 33.2 & 78.6 & 903 & 896 & 183 & 159 & 122.6 & \pm 17.9 \\
\hline 20 & SS Mesh & 78.6 & 118.5 & 913 & 901 & 90 & 76 & 170.1 & \pm 31.1 \\
\hline 20 & SS Mesh & 0.0 & 500.0 & 919 & 901 & 158 & 127 & 452.2 & \pm 17.5 \\
\hline 2 & Alumina & 0.0 & 11.9 & 904 & 902 & 14 & 12 & & \\
\hline 2 & Alumina & 11.9 & 52.1 & 904 & 899 & 14 & 13 & 28.6 & \pm 9.9 \\
\hline 2 & Alumina & 52.1 & 93.8 & 901 & 899 & 2.8 & 1.6 & 162.2 & \pm 37.1 \\
\hline 2 & Alumina & 93.8 & 128.9 & 900 & 899 & 17 & 11 & 148.7 & \pm 18.1 \\
\hline 2 & Alumina & 0.0 & 476.0 & 923 & 901 & 11 & 4.9 & 445.2 & \pm 44.9 \\
\hline
\end{tabular}




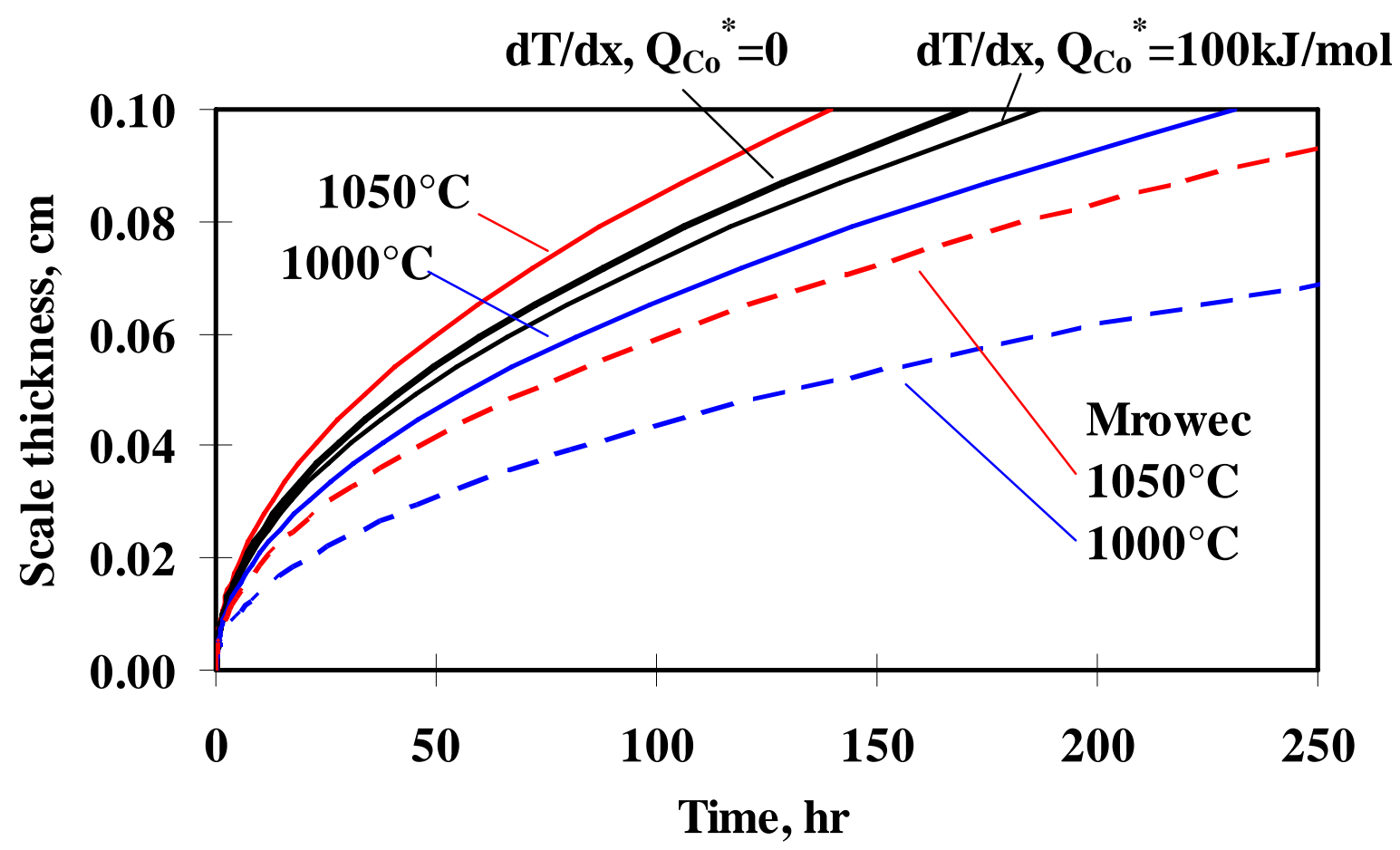

Figure 1. Isothermal and non-isothermal oxidation of cobalt in air as predicted by the integration of Eq. 8. The solid lines are from the model: isothermal predictions at $1000^{\circ} \mathrm{C}$ and $1050^{\circ} \mathrm{C}$, effects from a temperature gradient $(\mathrm{dT} / \mathrm{dx}, \mathrm{Q}=0)$, and the combined effects of a temperature gradient and heat of transport $(\mathrm{dT} / \mathrm{dx}, \mathrm{Q}=100 \mathrm{~kJ} / \mathrm{mol})$. The dashed lines are isothermal scale thicknesses at $1000^{\circ} \mathrm{C}$ and $1050^{\circ} \mathrm{C}$ derived from Mrowec and Prybyski. ${ }^{15}$ 


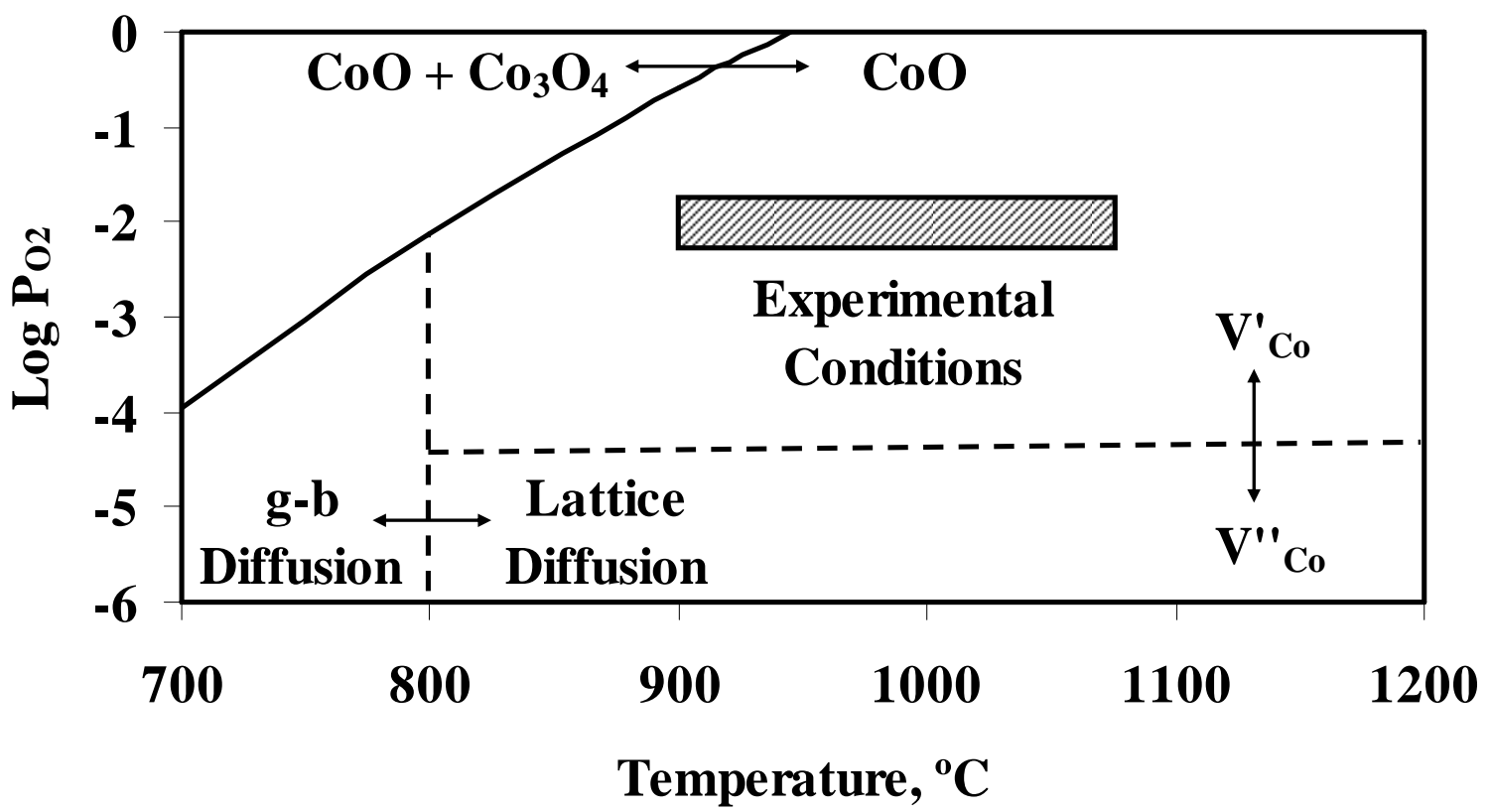

Figure 2. The temperature and oxygen partial pressure limits for oxidation experiments where $\mathrm{CoO}$ is the stable oxide, $\mathrm{V}^{\prime}{ }_{\mathrm{Co}}$ is the predominate point defect, a temperature where lattice diffusion should predominate. 


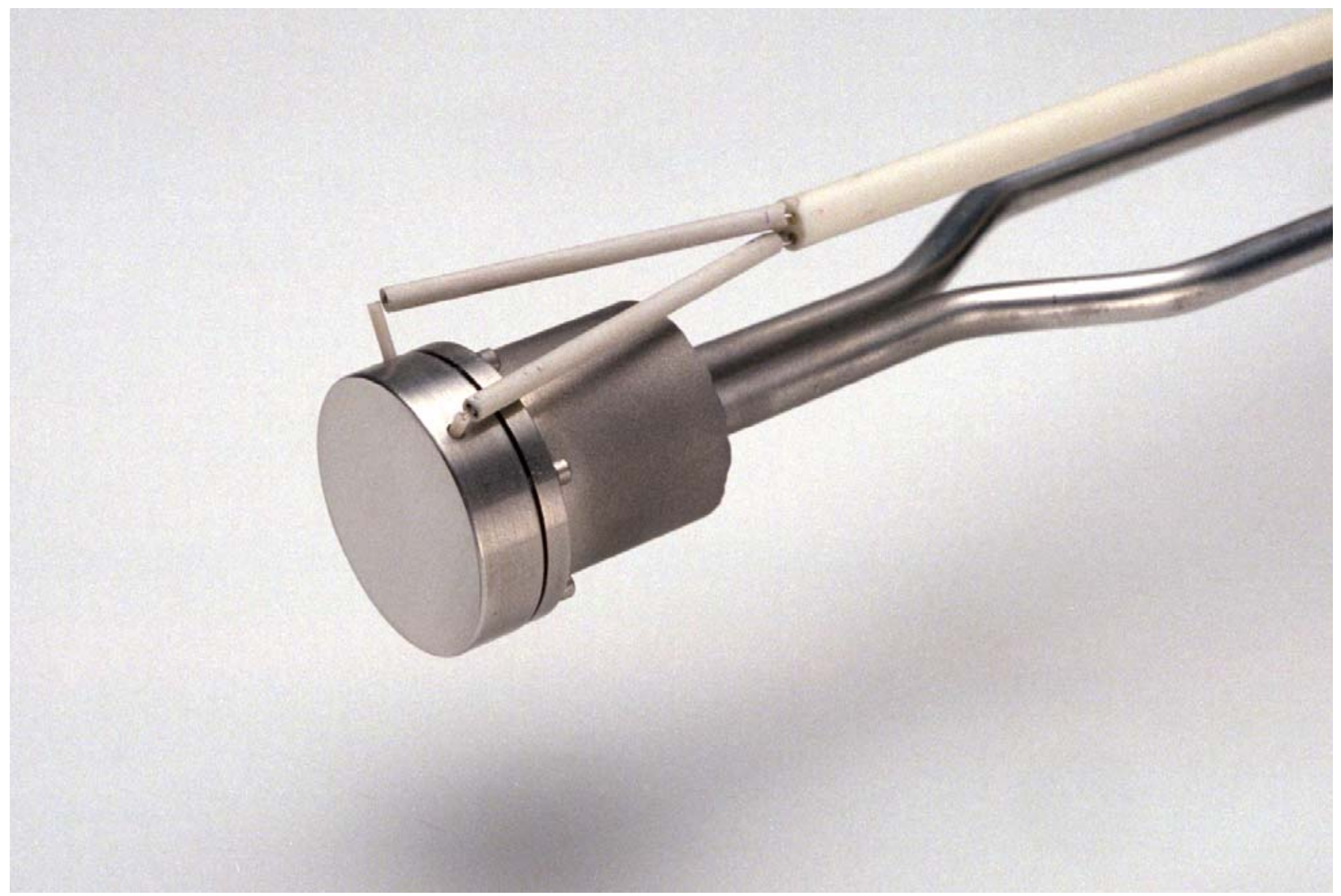

Figure 3. Sample assembly with a machined cobalt disk $(2.54 \mathrm{~cm}$ diameter $)$ with internal thermal couples and attached to an air-cooled chamber.

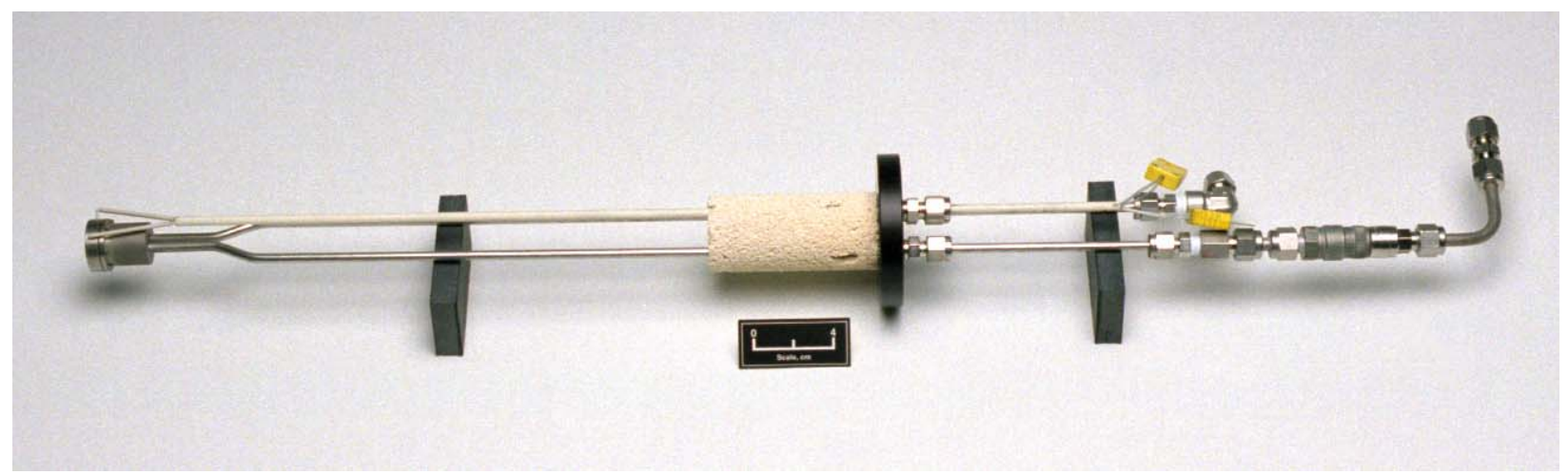

Figure 4. Sample assembly for insertion into a tube furnace. Shown without insulation wrap. Scale marker is $4 \mathrm{~cm}$. 


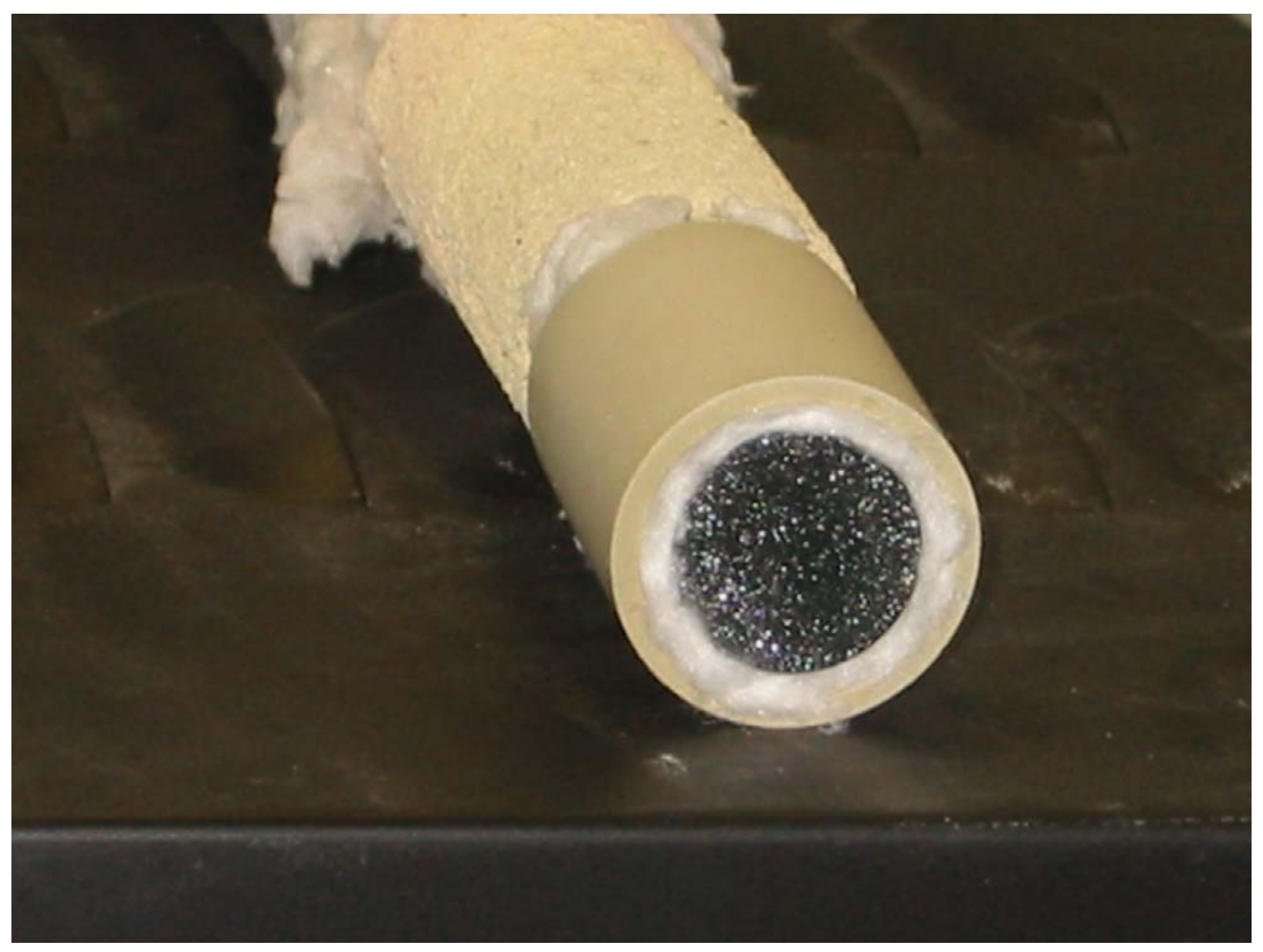

Figure 5. Sample assembly with insulation to approximate one-dimensional heat flow. 


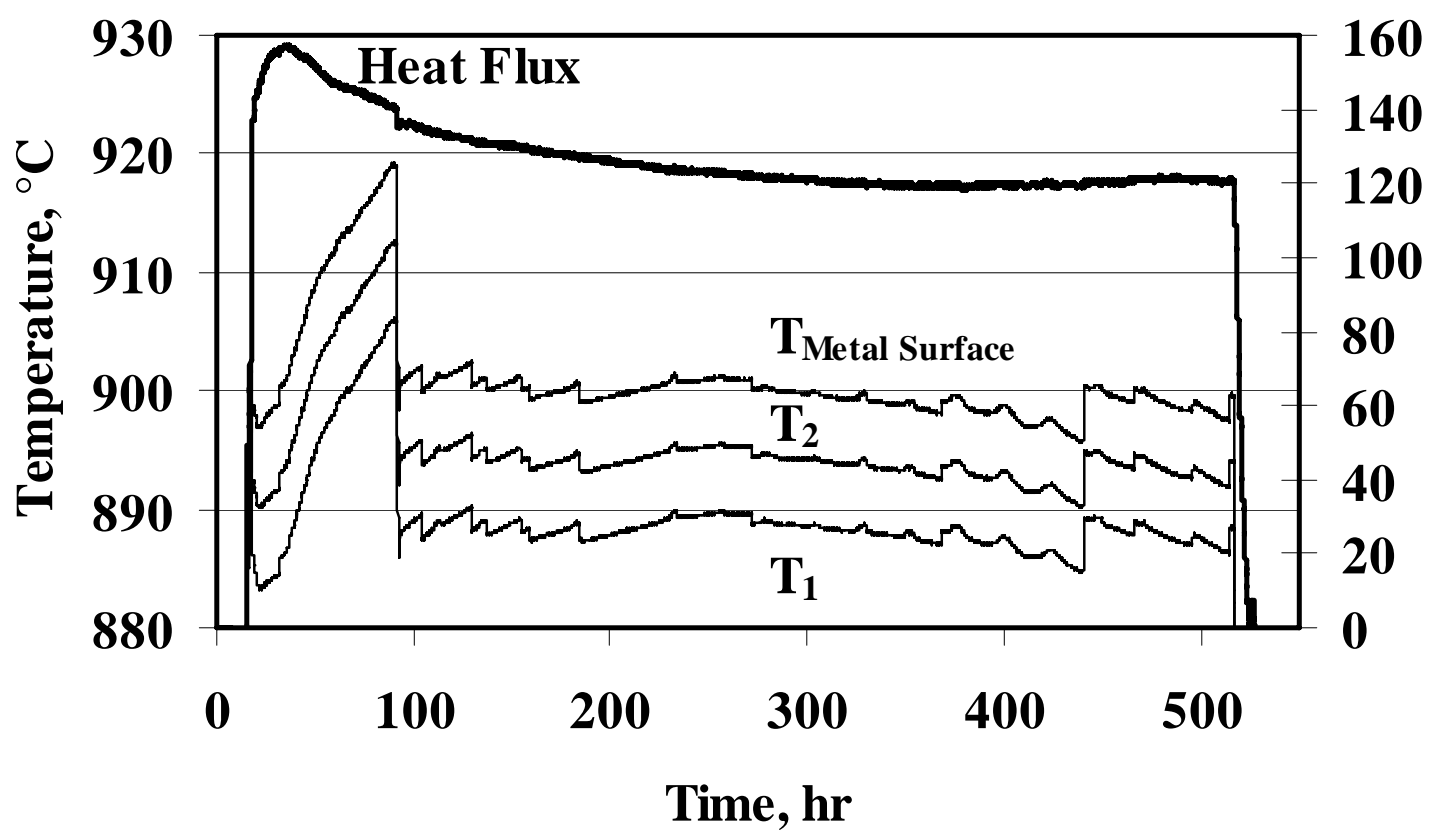

Figure 6. Oxidation of cobalt in a temperature gradient in $\mathrm{N}_{2}-1 \% \mathrm{O}_{2}$ with a mean metal surface temperature of $901^{\circ} \mathrm{C} . \mathrm{T}_{1}$ and $\mathrm{T}_{2}$ are measured and used to calculate $\mathrm{T}_{\text {Metal Surface }}$ using Eq. 15.

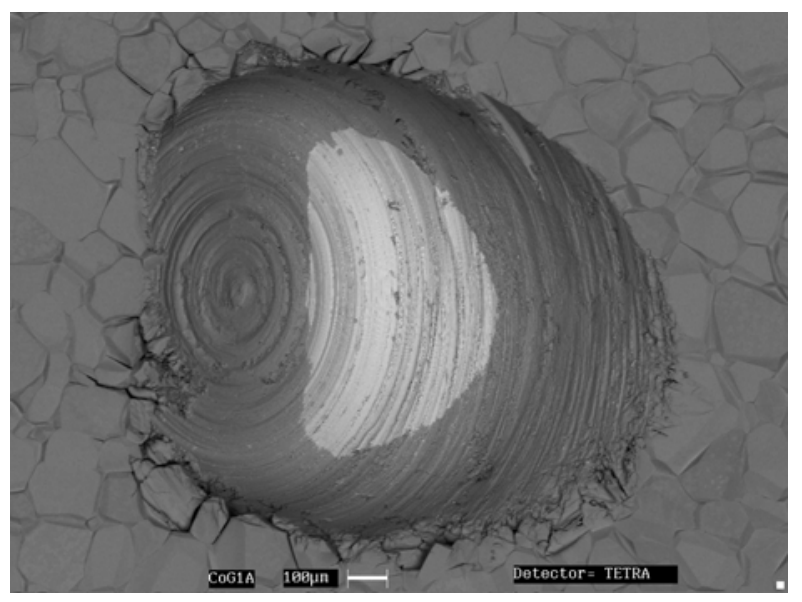

Figure 7. BSE image of a drilled nick (at $45^{\circ}$ ) in a cobalt disk after a close-to-isothermal exposure $\left(4.8 \mathrm{~kW} / \mathrm{m}^{2}\right)$ to $\mathrm{N}_{2}-1 \% \mathrm{O}_{2}$ for $476 \mathrm{hr}$ with a mean metal surface temperature of $901^{\circ} \mathrm{C}$.

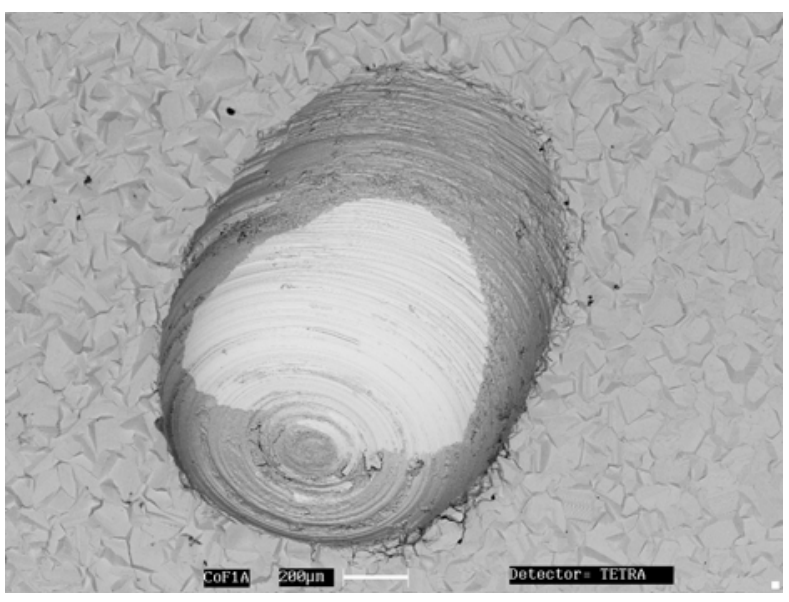

Figure 8. BSE image of a drilled nick (at $45^{\circ}$ ) in a cobalt disk after a heat flux exposure $(125.8$ $\mathrm{kW} / \mathrm{m}^{2}$ ) to $\mathrm{N}_{2}-1 \% \mathrm{O}_{2}$ for $500 \mathrm{hr}$ with a mean metal surface temperature of $901^{\circ} \mathrm{C}$. 


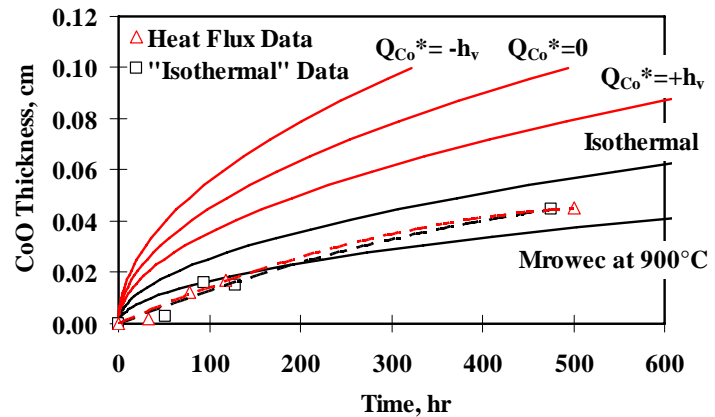

a)

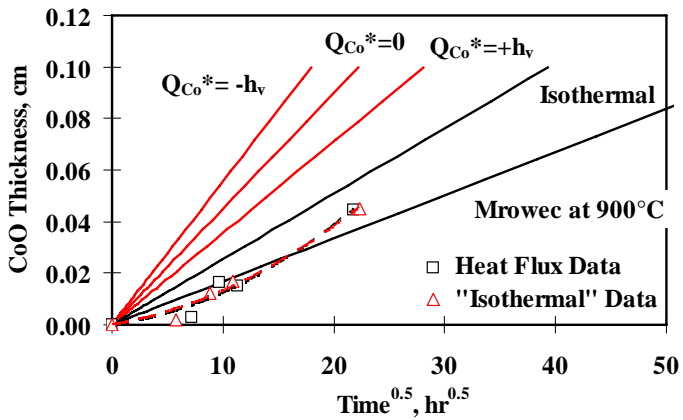

b)

Figure 9. Experimental results (data points and dashed lines) and calculated heat flux effects (upper four solid lines) for the oxidation of cobalt at $900^{\circ} \mathrm{C}$ with $\mathrm{N}_{2}-1 \% \mathrm{O}_{2}$. The isothermal line was calculated with $\mathrm{Q}_{\mathrm{Co}}{ }^{*}=0, \mathrm{~T}_{0}=900^{\circ} \mathrm{C}$, and $\mathrm{T}_{\mathrm{x}}=\mathrm{T}_{0}+10^{-6}{ }^{\circ} \mathrm{C}$. The other three lines were calculated with $\mathrm{T}_{0}=900^{\circ} \mathrm{C}, \mathrm{T}_{\mathrm{x}}=1080^{\circ} \mathrm{C}$ and three values of $\mathrm{Q}_{\mathrm{Co}}{ }^{*}$. The lowest solid line is the isothermal scale thicknesses at $900^{\circ} \mathrm{C}$ extrapolated from Mrowec and Prybyski. ${ }^{15}$ 